Article

\title{
The Impacts of Tourism Stays on Residents' Self-Reported Health: A Pan-European Analysis on the Role of Age and Urbanization Level
}

\author{
Anna Bornioli ${ }^{1, *(\mathbb{D})}$, Susan J. Vermeulen ${ }^{1} \mathbb{D}^{\mathbb{D}}$, Jeroen van Haaren ${ }^{1} \mathbb{D}$, Riccardo Valente ${ }^{2}$ and Giuliano Mingardo ${ }^{1}$ \\ 1 Erasmus Centre for Urban, Port and Transport Economics, Erasmus University Rotterdam, \\ 3062 PA Rotterdam, The Netherlands; s.j.vermeulen@ese.eur.nl (S.J.V.); vanhaaren@ese.eur.nl (J.v.H.); \\ mingardo@ese.eur.nl (G.M.) \\ 2 Department of Geography, Rovira i Virgili University, 43480 Vila-seca, Spain; riccardo.valente@urv.cat \\ * Correspondence: bornioli@ese.eur.nl
}

check for

updates

Citation: Bornioli, A.; Vermeulen, S.J.; van Haaren, J.; Valente, R.;

Mingardo, G. The Impacts of Tourism Stays on Residents' Self-Reported Health: A Pan-European Analysis on the Role of Age and Urbanization Level. Sustainability 2022, 14, 1157. https://doi.org/10.3390/su14031157

Academic Editors:

Mercedes Rodríguez-Fernández,

Yvon Bryan and Eva M. Sánchez-Teba

Received: 17 December 2021

Accepted: 17 January 2022

Published: 20 January 2022

Publisher's Note: MDPI stays neutral with regard to jurisdictional claims in published maps and institutional affiliations.

Copyright: (c) 2022 by the authors Licensee MDPI, Basel, Switzerland. This article is an open access article distributed under the terms and conditions of the Creative Commons Attribution (CC BY) license (https:// creativecommons.org/licenses/by/ $4.0 /)$.

\begin{abstract}
Understanding the impacts of tourism on the quality of life of residents is a priority for the sustainable tourism agenda, and is especially relevant to the COVID-19 recovery period. However, the evidence is poor, and it is not clear whether the outcomes vary among sociodemographic groups. This study fills this gap by proposing a pan-European analysis of the effects of tourism stays per 1000 residents (as a measure of tourism pressure) on self-perceived health at a regional level, based on data from Eurostat, the EU-SILC (European Union Statistics on Income and Living Conditions survey), and the LFS (Labor Force Survey). Multilevel models with random effects were used, including three levels: region, time, and region-time. Results show that tourism pressure may benefit self-reported health but only among residents aged over 50 years old living in rural contexts, or over 65 living in low density urban areas. As for younger groups (under 50) living in high density cities, tourism is longitudinally associated with worsened self-reported health. These results, which are supported by instrumental-variable estimations, suggest that urban residents and younger groups do not benefit from tourism. This might be due to a number of side effects related to increased living costs, precarious labour, and conflicts related to public space. Therefore, our findings challenge the narrative that urban tourism universally improves residents' quality of life. Considering the global urgency of creating healthier and more equitable post-COVID-19 cities and societies, tourism should be considered together with health and equity dimensions.
\end{abstract}

Keywords: tourism; health; sustainability; wellbeing; Europe; EU-SILC; multilevel model

\section{Introduction}

Tourism is an important aspect of life and produces important social, economic, and cultural outcomes for both travellers and host communities. Before the COVID-19 crisis, tourism was a booming industry and the sector was growing every year, with 1.5 billion global tourist arrivals in 2019 [1]. Tourism-and the lack of it-produce important impacts that are of an economic, social, cultural, and health nature. While extensive research has explored the positive impacts for the tourists (for reviews, see [2,3]), understanding the effects of tourism on local populations is equally important, if not of a higher priority, especially in the framework of present day debates on post-pandemic recovery. This is also reinforced by the growing focus around the notion of sustainability of tourism, defined as a careful utilization of resources that "meets the needs of present tourists and host regions while protecting and enhancing opportunities for the future" [4] (1998: 5). As a result, in the last decades, research has examined the economic, socio-cultural, and environmental impacts of tourism on community residents [2]. The general view is that host communities tend to recognize the economic benefits of tourism development, but hold some concerns on its potential social and environmental costs [5]. 
The tourism studies field has also recently focused on the impacts of tourism on the quality of life of residents. Quality of life has been used in the tourism studies field as an umbrella term referring to subjective wellbeing [3], life satisfaction [6], and happiness-terms that, in this literature, "are positively correlated and are often used interchangeably" [6]. The attention given to quality of life builds on a recent affective turn in the social sciences that puts emphasis on the overall welfare of individuals, not just on their wealth [7]. Health, happiness, and wellbeing have started to be recognized as important indicators of the success of nations [8], and policy makers have recently called for a broader range of measures of wealth, next to financial measures such as GDP. The study of the impact of tourism on the subjective measures of the quality of life of both residents and tourists has also become an important focus in the tourism studies field. With regards to tourism, the idea behind the focus on wellbeing is that the interactions between demand (visitors) and supply (the host community and tourism related local stakeholders) can generate cultural, physical, economic, and environmental impacts over time, and these can affect the wellbeing and quality of life of both tourist and residents [3]. For travellers, tourism is generally beneficial [3], to the point that specific forms of tourism have arisen, such as health tourism, wellness tourism, and medical tourism, finding their roots in the benefits that tourism can have for mental and physical health. However, another face of the coin related to tourism and health is the impact of tourism on the quality of life of local residents.

The evidence on the impacts of tourism on residents' quality of life is mixed. While case study investigations generally show that hosting communities hold positive perceptions of tourism, and believe that tourism has contributed to improving the local quality of life [9-14], some studies based on wider regions identified negative outcomes $[6,15,16]$. Starting from the former, Gursoy et al.'s [9] structural equation modelling study, based on data from users of a USA recreational area, found that support of host community is affected by, among others, the level of concern and perceived costs and benefits of the development of tourism. Research conducted in communities in Norway [10], Aruba [12] and Palma de Mallorca [13] reported communities' positive views on tourism. However, Rivera et al. [12] estimated that the positive impact of tourism on happiness, in the case of the Caribbean island of Aruba, only explained $4 \%$ of the happiness variance.

On the other hand, several international comparisons and quantitative studies identified negative quality of life outcomes produced by tourism. For example, in 2017 Ivlevs examined national trends of tourism and quality of life in Europe and concluded that, at a national level, international tourism arrivals are associated with a decrease in life satisfaction among national residents, while happiness levels were not affected [6]. According to the study, the residents most negatively affected were those living either in over-touristed countries, where tourist arrivals or tourism is rapidly growing, or in rural areas. The evidence also seems to indicate that the effects of tourism on quality of life are complex and also depend on the time frame considered and the level of tourism flows. In this regard, a recent Spanish study conducted on pre-COVID-19 data [15] concluded that tourism arrivals have a negative influence on residents' health in the short term, and a positive impact in the long term. It was found that a $1 \%$ growth in tourism arrivals explained a $0.8 \%$ decrease in residents' health in the short term and a $1 \%$ increase in residents' health in the long term [15]. The authors suggested that, while short term health might be affected by the negative side effects of tourism, such as overcrowding and traffic and an increase in crime levels and infectious disease, in the long-term physical health and longevity might benefit from positive experiences and social interactions with tourists. In addition, results by Tokarchuk et al. [16], based on German data, suggest that the relationship between tourism and residents' satisfaction with life is not linear. According to the authors, the effect of tourism stays on residents' wellbeing is positive "until a certain threshold [of tourism stays] is reached" [16] (p.7). In conclusion, the evidence seems to indicate that tourism can have positive impacts on residents' health and wellbeing but only within a certain threshold of tourism growth $[16,17]$. 
These contrasting effects can be explained by the fact that tourism development can affect quality of life in different ways. The first domain that can explain the outcomes of tourism relates to economic development and wealth. Tourism development usually goes with more jobs and increased incomes. Globally, the tourism industry represents 1 in every 10 jobs across the globe, and 30\% of world trade in services [18]. In Europe, around 6\% of the labour force is employed in the tourism industry. Given that wealth, living and working conditions are well known socio-determinants of health [19], it can be assumed that tourism can have a positive effect on health and wellbeing by generating income. However, tourism might also increase pressure on living and working conditions by increasing living costs and job instability. Recent works have highlighted how tourism-led gentrification can increase cost of life, especially housing-related costs $[20,21]$. In addition, tourism development can also generate detrimental effects in terms of job insecurity and precarity and increased cost of life [1]. A second domain relates to environmental living conditions: tourism development has been associated with an improvement of infrastructures, transportation networks, the accessibility of public space, and recreation opportunities at the destination [3]. On the other hand, in relation to environmental conditions, tourism can also have negative impacts, including increasing congestion, environmental pollution, and overcrowding-which all might negatively influence quality of life and wellbeing [21]. There are also the potential indirect, spill over effects of tourism on health, generated by the noise, grime, waste and environmental pollution produced by tourism [22,23].

Based on these complex processes, we suggest that the social consequences of tourism are likely to distribute quite unevenly among social groups. However, previous studies examined the impacts of tourism at a population level, rather than focusing on specific groups $[6,15,16]$. Instead, the literature on gentrification indicates that it is specific sociodemographic segments that can suffer negative consequences of tourism [20,21]. Arguably, age and urbanization level are two characteristics that deserve further attention. For instance, taking Nguyen, Rahtz and Shultz [24] into account, elderly residents might appreciate tourism and the wealth it brings, as they have experienced economic deprivation in the past. On the other hand, young residents might enjoy recreational opportunities linked with tourism growth, but they are also more likely to hold precarious jobs in the tourism industry [25], with all the negative consequences on health that precariousness entails. In addition, while cities are especially prone to increased precarity and cost of life, led by gentrification $[20,21]$, rural areas might benefit from improved environmental conditions and investment in infrastructure. These processes have become even more timely in the COVID-19 era, as the pandemic and related lockdowns have been deteriorating the health of global populations. For this reason, it is important to understand whether tourism recovery can contribute to improving residents' health or not, thus informing strategies for the recovery era.

Building on these reflections and on the need to inform tourism and public health policies for the COVID-19 recovery era, the current study adds to the existing literatures in two ways. First, it estimates quantitative tourism impacts on self-perceived health in the European continent, based on an extremely refined geographical scale (regional scale modelled around urbanization level). Second, it does so by contemplating possible differences among age groups and tourism destinations with different degrees of urbanization. We focus on self-reported health as a subjective indicator that describes individuals' satisfaction with their health status, which is a well-established predictor of morbidity, health service use and mortality, used to assess life expectancy [26]. The hypotheses were:

Hypotheses 1 (H1). Tourism stays per capita increase the regional share of healthy residents.

Hypotheses 2 (H2). There are differences between age groups in the effects of tourism on selfreported health.

Hypotheses 3 (H3). There are differences between degree of urbanization groups (urban, town, rural) in the effects of tourism on self-reported health. 


\section{Materials and Methods}

The study is part of the SMARTDEST H2020 research project [27]. We assessed regional self-reported health as a function of overnight stays per capita, as well as controls, according to the following (Figure 1):

$$
\begin{aligned}
H_{\text {iuat }}=\beta_{0}+ & \beta_{1} \ln (S)_{i u t}+\beta_{2} P_{\text {iuat }}+\beta_{3} B_{\text {iuat }}+\beta_{4} I_{\text {iuat }}+\beta_{5} C_{i}+\beta_{6} G_{i t}+\beta_{7} L_{i t}+\beta_{8} Q_{i t} \\
& +\beta_{9} A+\beta_{10} U+\beta_{11} \ln (S)_{i u t} * A+\beta_{12} \ln (S)_{i u t} * U+\varepsilon_{i t}+\varepsilon_{i t} L_{i t}+\varepsilon_{i t} Q_{i t} \\
& +v_{t}+u_{i}
\end{aligned}
$$

where:

$H_{\text {iuat }}=$ share of healthy individuals in region $\mathrm{i}$ with level of urbanization $\mathrm{u}$ at time $\mathrm{t}$ in age group a

$\ln (S)_{i u t}=$ natural log of tourism pressure (overnight stays per thousand inhabitants) in region $\mathrm{i}$ with level of urbanization $\mathrm{u}$ at time $\mathrm{t}$

$P_{\text {iuat }}=$ poverty rate in region $\mathrm{i}$ with level of urbanization $\mathrm{u}$ at time $\mathrm{t}$ in age group a

$B_{\text {iuat }}=$ the share of people experiencing a housing burden in region i with level of urbanization $\mathrm{u}$ at time $\mathrm{t}$ in age group a

$I_{\text {iuat }}=$ the share of people receiving income from rent in region $\mathrm{i}$ with level of urbanization $\mathrm{u}$ at time $\mathrm{t}$ in age group a

$C_{i}=$ dummy indicating if region $\mathrm{i}$ is a capital region

$G_{i t}=$ GDP per capita in region $\mathrm{i}$ at time $\mathrm{t}$

$L_{i t}=$ dummy indicating if region $\mathrm{i}$ at time $\mathrm{t}$ has a high LQ

$Q_{i t}=$ dummy indicating if region $\mathrm{i}$ at time $\mathrm{t}$ has a low LQ

$A=$ age group (15-29; 30-49; 50-64; over 65)

$U=$ urbanisation type (urban; town; rural)

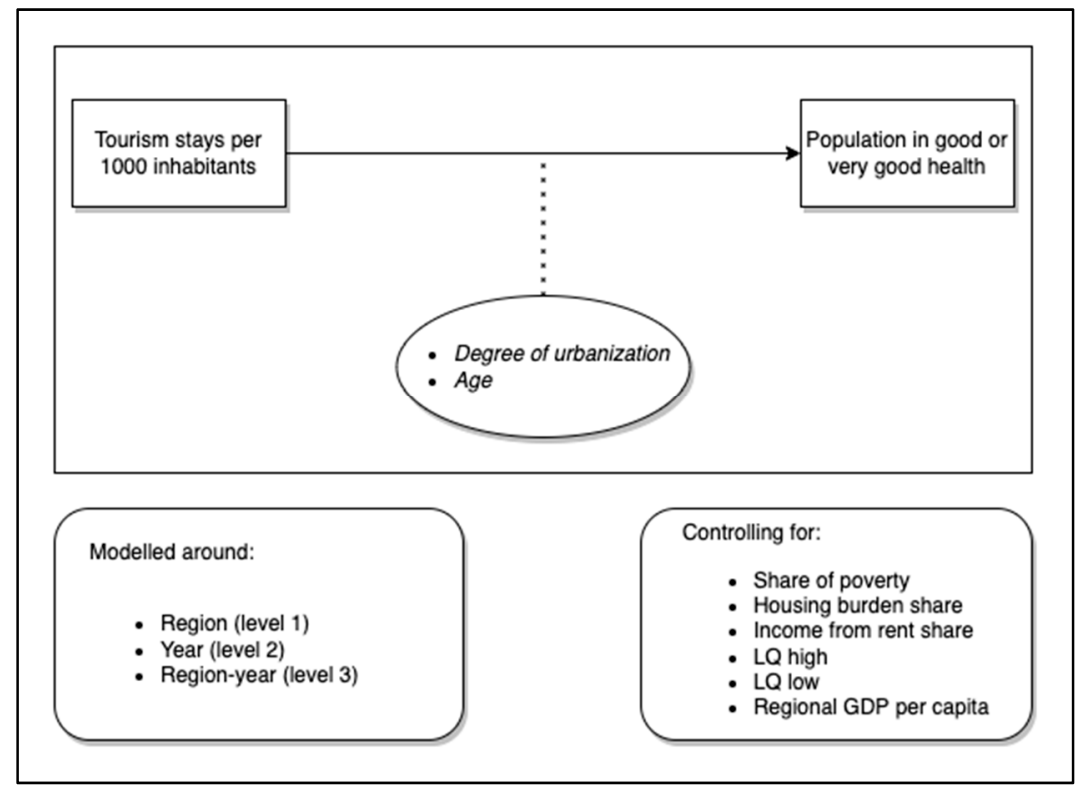

Figure 1. Conceptual model.

The proposed analysis assessed whether tourism pressure, defined as the number of overnight stays per 1000 inhabitants, might be associated with an improvement or a worsening of regional self-perceived health in Europe among twelve specific groups defined by age (15-29, 30-49, 50-64, and over 65 years old) and urbanization level (urban, town, rural). The empirical tests are based on data from Eurostat, and two surveys on living (EU-SILC) and working conditions (LFS) at a pan-European level. The time frame of this study is 2013-2018. 


\subsection{Data Sources}

A combined dataset with data on tourism, social indicators, and other regional characteristics was created with different sources (Eurostat, EU-SILC, LFS). The final dataset includes 164 NUTS (Nomenclature of Territorial Units for Statistics, 2016 version) regions (69 NUTS1 and 95 NUTS2), which cover 34 European countries: EU 27, UK, Albania, Serbia, North Macedonia, Montenegro, Norway, and Iceland. A preliminary version is publicly available [28]. The dataset includes data in a combination of two geographical levelsNUTS1 and NUTS2-depending on the availability of EU-SILC data. NUTS1 regions are regions with 3 to 7 million inhabitants, while in NUTS2 regions residents are roughly 800 thousand to 3 million inhabitants [28]. Within the NUTS classification, a DEGURBA (DEGree of URBAnization) classification has been provided by Eurostat since 2012, which categorizes areas according to their level of urbanization. This classification includes three categories [29]: densely populated areas (or cities); intermediate density areas (towns and suburbs) and thinly populated areas (rural). Data on this level was used for EU-SILC, LFS and tourism statistics of Eurostat.

The research team created the dataset using $\mathrm{R}$ statistical package [30]. For the automatic extraction of the Eurostat data, the package "eurostat" in R [31] was employed. In addition to this, we used packages such as "tidyverse" and "sf" to merge the data at a NUTS1 and NUTS2 level [32,33]. For details on the dataset, missing data, and imputation procedures, please refer to [34]. We estimated our models on 76 different NUTS regions, of which 13 were NUTS1 regions and 63 NUTS2 regions.

\subsection{Dependent Variable}

The dependent variable was the share of population who reports being in "good" or "very good" healthy, aggregated at DEGURBA level in each region. This was derived from the EU-SILC, which provides information on social, health and economic conditions from large population samples, based on surveys conducted every year in each country and then harmonized [35]. EU-SILC has collected individual data for a sample of persons aged 16 years or older since 2005 who are asked, among other questions, to rate their health based on the following question: "How is your health in general?", with a five-point Likert scale response: (i) very good; (ii) good; (iii) fair; (iv) bad; (v) very bad. The dependent variable healthy share, retrieved from EU-SILC, refers to the percentage of respondents who perceived their health to be good or very good. Two reference years were taken: 2013 and 2018. Healthy share and other EU-SILC variables were extracted for 4 age groups (15-29, 30-49, 50-64, and over 65), and for 3 urbanization levels (urban, town, rural), and then converted into a long format with age groups and urbanization level as categorical variables. For all the data from the EU-SILC dataset, the cross-sectional weight RB050 was applied, which should lead to a more accurate estimation of the overall population, since some groups might be over- or underrepresented in the EU-SILC dataset.

\subsection{Independent Variable}

The independent variable labelled "tourism pressure" was derived from the number of overnight stays at tourism accommodation establishments per capita (per 1000 residents), at DEGURBA level within a region. This was based on Eurostat's number of annual overnight stays at tourism accommodation establishments, which includes hotels, holiday, and other short-stay accommodation, camping grounds, recreational vehicle parks, and trailer parks. Numbers were relativized to local residents in order to obtain a measure of tourism pressure, as opposed to the absolute values-also, given the varying size of regions; the natural logarithm was used. While some previous studies [6,15] employed the number of arrivals as an independent variable, we selected the variable overnight stays, which has the advantage of encapsulating the duration of tourism stays in a given region, thus being a more refined indicator of tourism presence that can describe the real impact on resident populations. 


\subsection{Controls}

Controls from the EU-SILC include the poverty indicator (the share of total population that is unable to afford some items considered by most people to be desirable or even necessary to lead an adequate life), the financial burden of the total housing costs (measured as the percentage of persons in the total population living in a dwelling with a financial burden due mortgage repayment, rent, insurance and service charges), and a variable on the income from rent (the percentage of persons receiving income from renting out a property). Two dummies were also defined based on the location quotient (LQ) calculated from LFS data. This indicates whether a specific industry (in this case, tourism) is under or over-represented in a given region compared to a wider area (in this case, Europe). A value greater than 1 indicates that the regional tourism industry employment is over-represented compared to the European picture. The LQ dummies indicate regions where tourism is under-represented and over-represented, respectively. Regional GDP per capita, from Eurostat, and age groups, from EU-SILC, were also included as controls.

\subsection{Model}

Multilevel longitudinal models with random effects were used, following guidelines by Schmidt-Catran and Fairbrother [36]. Three-level models were included, which correspond to the hierarchical data structure (Figure 2): characteristics at region level (level 1), within time (level 2), and NUTS-year level (level 3) for characteristics which vary over time within regions. Sensitivity analyses were also performed with the addition of a fourth model to take into account country-level characteristics. The results did not vary; these are available upon request.

TIME

NUTS ID
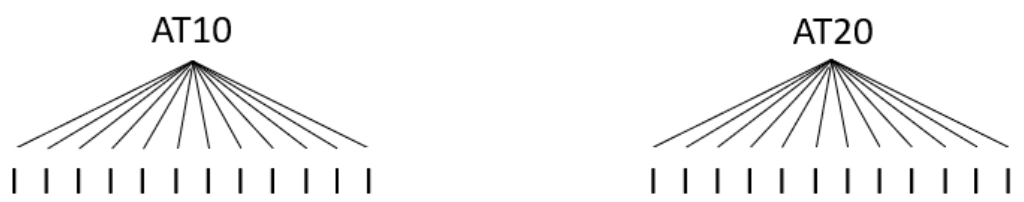

Figure 2. Multilevel model.

\subsection{Instrumental Variable Regressions}

To mitigate potential endogeneity issues and establish causal evidence, instrumental variable (IV) regressions were employed. The method employs an "instrument" variable that fulfils three conditions [37,38]: (1) it is associated with the regressor variable (tourism pressure); (2) it does not affect the dependent variable, except through the independent variable; and (3) it does not have causes shared with the dependent variable. We selected two instruments for tourism pressure: the number of regional heritage sites per root of $\mathrm{km}^{2}$; and the number airports served by Ryanair in the region per root of $\mathrm{km}^{2}$. While it was expected that the two instruments would predict regional tourism pressure, there is no plausible causality of the instrument on the regional share of healthy individuals nor a correlation of the error term of regional tourism pressure. This should be conditioned on the other covariates in the regression. Therefore, two IV estimations were computed: one with controls and one without controls. The estimation included a first stage, in which tourism pressure is regressed on the instrument and covariates, and a second stage, in which the predicted values of the first stage dependent variable are used as a regressor with the control variables. The Hansen J test of overidentification was then employed to 
confirm whether the instruments are exogenous (uncorrelated with the error term). The IV method has been employed previously in tourism research (see for example [6]).

\section{Results}

Descriptive statistics are displayed in Table 1. Overnight stays per capita varied greatly among European regions, as well as the share of healthy residents.

Table 1. Descriptive statistics (2018).

\begin{tabular}{|c|c|c|c|c|c|}
\hline Statistic & $\mathbf{N}$ & Mean & St. Dev. & Min & $\operatorname{Max}$ \\
\hline $\ln$ (tourism pressure) & 340 & 8.54 & 0.923 & 5.74 & 12.104 \\
\hline City & 121 & 8.452 & 0.715 & 5.74 & 10.757 \\
\hline Town & 110 & 8.366 & 0.925 & 6.871 & 11.447 \\
\hline Rural & 109 & 8.814 & 1.060 & 5.92 & 12.104 \\
\hline $\begin{array}{l}\text { Share of population in } \\
\text { good or very good health }\end{array}$ & 1359 & 0.686 & 0.220 & 0.03 & 1 \\
\hline $15-29$ & 340 & 0.909 & 0.073 & 0.347 & 1 \\
\hline $30-49$ & 340 & 0.808 & 0.081 & 0.483 & 1 \\
\hline $50-64$ & 340 & 0.620 & 0.126 & 0.231 & 1 \\
\hline Over 65 & 339 & 0.404 & 0.134 & 0.03 & 0.749 \\
\hline $\begin{array}{l}\text { Share of population in } \\
\text { good or very good health }\end{array}$ & 1359 & 0.686 & 0.220 & 0.03 & 1 \\
\hline City & 484 & 0.69 & 0.209 & 0.127 & 1 \\
\hline Town & 436 & 0.685 & 0.222 & 0.07 & 1 \\
\hline Rural & 435 & 0.679 & 0.23 & 0.03 & 1 \\
\hline Share of housing burden & 1359 & 0.762 & 0.217 & 0 & 1 \\
\hline $15-29$ & 340 & 0.793 & 0.206 & 0 & 1 \\
\hline $30-49$ & 340 & 0.785 & 0.201 & 0 & 1 \\
\hline $50-64$ & 340 & 0.751 & 0.219 & 0 & 1 \\
\hline Over 65 & 339 & 0.720 & 0.235 & 0 & 1 \\
\hline Poverty rate & 1359 & 0.097 & 0.09 & 0 & 0.53 \\
\hline $15-29$ & 340 & 0.061 & 0.063 & 0 & 0.44 \\
\hline $30-49$ & 340 & 0.155 & 0.095 & 0 & 0.53 \\
\hline $50-64$ & 340 & 0.143 & 0.084 & 0 & 0.45 \\
\hline Over 65 & 339 & 0.029 & 0.032 & 0 & 0.18 \\
\hline $\begin{array}{l}\text { Share of population which } \\
\text { retrieves income from rent }\end{array}$ & 1359 & 0.105 & 0.080 & 0 & 0.75 \\
\hline $15-29$ & 340 & 0.084 & 0.074 & 0 & 0.48 \\
\hline $30-49$ & 340 & 0.090 & 0.068 & 0 & 0.49 \\
\hline $50-64$ & 340 & 0.118 & 0.073 & 0 & 0.41 \\
\hline Over 65 & 339 & 0.127 & 0.096 & 0 & 0.75 \\
\hline Location Quotient & 122 & 1.188 & 0.583 & 0.34 & 4.04 \\
\hline GDP per inhabitant & 122 & $27,556.46$ & $10,924.630$ & $11,315.72$ & $69,669.97$ \\
\hline
\end{tabular}

Notes: Eurostat and EU-SILC data was provided with three decimal digits; values of zero indicate values that are smaller than 0.001 .

\subsection{Multilevel Models}

Table 2 displays the multilevel model output for the reference category 30-49 years old living in cities. In Table 3, the coefficients of the main predictor, tourism pressure, are presented for each age and DEGURBA group. In cities, for the age group 30-49, tourism pressure is a negative, statistically significant predictor of the healthy share, c.p. This is also the case for the 15-29 age group (Table 3). In towns, tourism pressure is a positive, statistically significant predictor for the age group over 65. This is also the case in rural areas, as tourism pressure is a positive statistically significant predictor for the age groups 50-64 and over 65. For the age groups above 49 years old living in cities, the age groups under 65 living in towns, and the age groups under 50 living in rural areas, there is no statistically significant effect. 
Table 2. Multilevel model: Percentage of population in good or very good health.

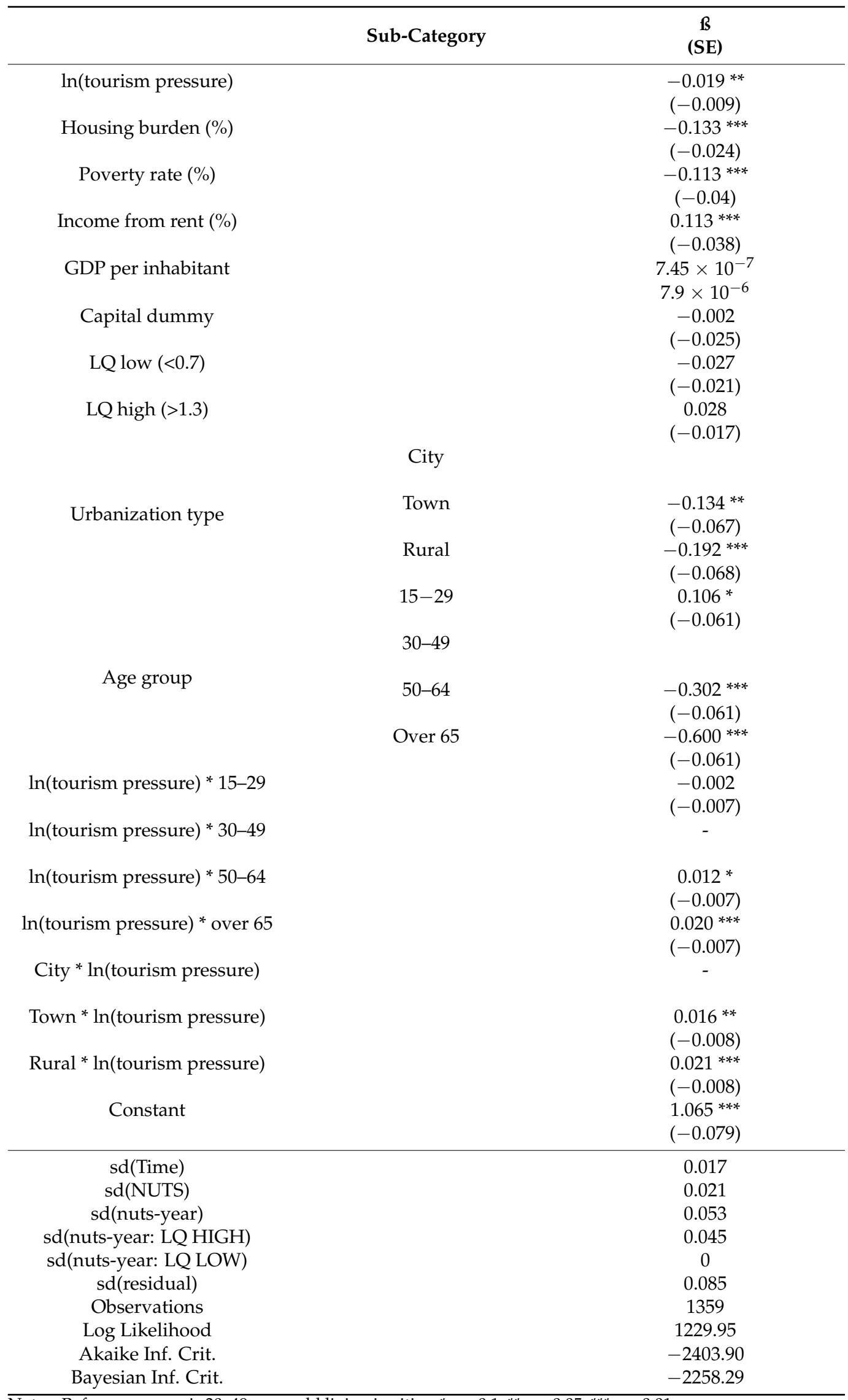

Notes: Reference group is $30-49$ years old living in cities. ${ }^{*} p<0.1 ;{ }^{* *} p<0.05 ;{ }^{* * *} p<0.01$. 
Table 3. Multilevel models summary of coefficients for each reference group. Tourism pressure effects on percentage of population in good or very good health.

\begin{tabular}{cccc}
\hline Urbanization Level & Age & $\boldsymbol{\beta}$ & SE \\
\hline \multirow{3}{*}{ City } & $15-29$ & $-0.021^{* *}$ & $(-0.009)$ \\
& $30-49$ & $-0.019^{* *}$ & $(-0.009)$ \\
& $50-64$ & -0.007 & $(-0.009)$ \\
& $>65$ & 0.001 & $(-0.009)$ \\
Town & $15-29$ & -0.005 & $(-0.007)$ \\
& $30-49$ & -0.003 & $(-0.007)$ \\
& $50-64$ & 0.009 & $(-0.007)$ \\
& $>65$ & $0.017^{* *}$ & $(-0.007)$ \\
Rural & $15-29$ & 0.001 & $(-0.007)$ \\
& $30-49$ & 0.002 & $(-0.007)$ \\
\hline
\end{tabular}

${ }^{*} p<0.1 ;{ }^{* *} p<0.05 ; * * * 0.01$.

In all models, income from rent is associated with a higher share of healthy individuals. A negative effect on healthy share is identified for poverty rate and housing burden. As expected, the healthy share is negatively associated with age as it tends to decrease with older age. As for degree of urbanization, cities areas tend to have a significantly higher share of population in good or very good health.

\subsection{Instrumental Variable Regressions}

Table 4 displays the results for the models estimated with the instrumental variable technique. The instruments (the number of regional heritage sites per root of $\mathrm{km}^{2}$; and the number of Ryanair airports in the region per root of $\mathrm{km}^{2}$ ) are a strong positive predictor of tourism pressure, with the values of the first-stage $F$ test of the excluded instrument exceeding the commonly accepted threshold value of 10 [37]. The second-stage results of the instrumental variable estimation show the effects on regional health. Model 1 includes controls, except for GDP and LQ, as these might be related to the decision process of Ryanair to open a new airport. Model 2 does not include any control. The effects of age and DEGURBA are absorbed in the fixed effects of the model. Both models suggest that tourism pressure has a positive effect on the share of healthy residents.

Table 4. Instrumental variable estimation.

\begin{tabular}{ccc}
\hline Variables & Model 1 & Model 2 \\
\hline $\ln$ (tourism pressure) & $0.188^{*}$ & $0.235^{* * *}$ \\
& $(0.113)$ & $(0.0819)$ \\
Share of poverty & -0.0429 & \\
& $(0.0483)$ & \\
Share of housing burden & -0.0893 & \\
& $(0.0617)$ & 0.0164 \\
Share of income from rent & 0.0304 & $(0.0135)$ \\
Time $=$ 2013 (reference category is 2018) & $(0.0808)$ & 2188 \\
& 0.0141 & 1094 \\
\hline Observations & $(0.0207)$ & 2188 \\
Number of n_unique_id & 1094 &
\end{tabular}


Table 4. Cont.

\begin{tabular}{ccc}
\hline Variables & Model 1 & Model 2 \\
\hline Fixed Effects & Yes & Yes \\
Heritage per 1000 km $\mathrm{km}^{2}$ & Yes & Yes \\
Ryanair Airports per $1000 \mathrm{~km}$ & Yes & Yes \\
Controls & Yes & No \\
Type LQ & None & None \\
\hline First Stage F-Stat & 28.70 & 29.04 \\
Kleibergen Paap Lm & 5.687 & 5.597 \\
$p$ value Kleibergen Paap & 0.0582 & 0.0609 \\
Hansen J & 0.0915 & 0.0575 \\
$p$ value Hansen J & 0.762 & 0.811 \\
\hline
\end{tabular}

Robust standard errors in parentheses, ${ }^{* * *} p<0.01,{ }^{* *} p<0.05,{ }^{*} p<0.1$.

\section{Discussion}

This study explored the effects of tourism pressure on the self-perceived health of residents in Europe, based on combined data from Eurostat, EU-SILC, and LFS. The analysis covered 34 countries and 164 regions over two reference years (2013 and 2018). We hypothesized that tourism stays per capita would increase the regional share of healthy residents (H1), and that the effects of tourism on self-reported health would be heterogeneous among age groups (H2) and degree of urbanization groups (urban, town, rural) (H3). H1 was partially confirmed, as the health impacts were positive only among older groups living in towns or rural areas. Among individuals under 50 and urban dwellers, tourism pressure tended to be negatively associated with self-reported health. $\mathrm{H} 2$ and $\mathrm{H} 3$ were confirmed, as the effects of tourism pressure on the share of residents reporting good or very good health were heterogenous depending on age groups and urbanization level. The causal nature of these associations is supported by instrumental variable estimations, where tourism pressure was predicted by the number of regional heritage sites per root of $\mathrm{km}^{2}$ and the number of Ryanair airports in the region per root of $\mathrm{km}^{2}$. Previous research provides contrasting results, indicating that in some cases tourism can reduce the life satisfaction [6] and health [15] of residents, and in other cases improve quality of life [17,39]. We add to existing evidence that the effects of tourism on health are not homogeneous among residents, but rather vary depending on age and urbanization groups. Hence, these results highlight the unequal outcomes, in terms of self-perceived health, generated by tourism. The results are discussed below.

The effect of tourism stays on health varied in relation to a population's age and urbanization level. Starting from the latter, the analyses showed that, in urban contexts specifically, tourism stays had a negative or null effect on residents' health, while in towns and rural areas the association tended to be positive. The negative outcomes in cities can be explained by two aspects. First, it is possible that, in urban environments, tourism flows worsen issues of overcrowding, traffic congestion, and increase in crime levels-which might all generate a negative outcome on health. Second, in urban contexts, tourism gentrification, just like other forms of gentrification [40,41], might have an important role. Scholars' recent contributions on overtourism - a situation in which certain physical, ecological, social, economic, psychological, and/or political capacity thresholds are exceeded [42,43] —and tourism-led gentrification - the process of the transformation of residential areas into leisure spaces for visitors, threatening the right to "stay put" of existing populations $[21,40,44]$ have offered a political and deromanticized view on role of the visitor economy for local communities. It has been suggested that tourism might increase pressures on living and working conditions by rising living costs $[20,21]$ and increasing job instability $[45,46]$, and that tourism can generate conflicts in the uses of public space, congestion, environmental pollution, and overcrowding [22,47,48], thus worsening living and working conditions [19]. These ideas are also in line with the suggestion offered by multiple scholars, that tourism can contribute to quality of life up to a certain level of tourism development $[6,16,17]$. We add to this that it is urban tourism specifically that might be disruptive for residents' health. 
In regard to the differential effects of tourism on age groups, it is possible that, for younger urban generations, tourism development and related gentrification significantly increase the financial burden of housing and living costs, without counterbalancing with substantial income. These findings are in line with the growing body of evidence on the detrimental effects of gentrification on low-income groups [44] and on urban inequalities [49,50]. Housing might be a key dimension to consider. Short term rentals, such as Airbnb, have important consequences for the housing market, as they can drive rents and house prices [22,51,52] and subsequently produce loss in rental housing [52] and the collective displacement of residents, thus exacerbating inequalities [20].

The other side of the coin is that, for older individuals living in towns and rural areas, tourism pressure was associated with positive health outcomes. While previous research conducted in European and US neighbourhoods highlighted the tourism and gentrification produced quality of life issues for older residents [39], overall individuals aged 50 and above tend to be more established financially and might also benefit from extra income related to tourism. In addition, rural and town contexts tend to be less dense and might be less sensitive to pressure from both tourism and gentrification.

Considering the aggregate nature of the data, another possible explanation for these intergenerational and residential differences is self-selection. Tourism regions attract not only tourists, but also residential and leisure mobilities and migration flows [53]. While town and rural contexts might attract wealthy mature workers and individuals approaching retirement, likely in good health, urban contexts tend to attract not only high-skilled workers, but also low-skilled workers who need to improve their social, economic, and health conditions, especially among young individuals who are seeking job opportunitiesincluding in the tourism industry. With regards to older groups, these mechanisms are equally problematic, as the results might suggest that the displacement of vulnerable groups is taking place from tourism cities to non-tourism places, with detrimental health and social consequences for these groups [20].

This study offers several contributions. First, it is a novel pan-European examination of how tourism development influences the self-perceived health of regional populations, and it offers a novel contribution to the limited literature on tourism and resident quality of life based on secondary data. Second, it contributes to the limited evidence on potential tourism impacts in terms of age and place of residence, and on how gentrification-related phenomena impact health and what social groups are most affected-a research gap identified in recent reviews [44,49,54,55]. While recent qualitative accounts or case-studies [40,41] described the possible negative consequences of tourism on residents' health, this study provides a novel comparative evidence based on secondary data and identifies specific sociodemographic group who are at risk of social exclusion. A key result that emerged is that urban tourism can generate negative outcomes on residents' health. Given the growing trends of tourism and gentrification in European and global cities, understanding how these may promote or hinder health is essential, to contribute to global public health goals for healthy cities.

From a methodological perspective, our study is robust, as it is based on longitudinal mechanisms that are also supported by instrumental variable methods. It is based on the most rigorous pan-European data sources available (EU-SILC, Eurostat, LFS), which have been harmonized at the pan-European level and are representative of European populations, and findings are generalizable to the whole European population. In addition, while previous research employed national-level data on tourism and health [6] or looked at national contexts $[15,16,40]$, our analyses covered the majority of the European regions and took the most refined possible geographical level (the regional scale), dictated by data availability, further modelled around the urbanization level. Such a scale is more refined and allows distinguishing the processes taking place in tourist and non-tourist areas [6] and allows comparing between regions in Europe. Such a rigorous design allowed us to identify two factors-age and urbanization type-that can define the winners and losers of tourism. 


\section{Policy Suggestions and Limitations}

Several major policy implications can be drawn from these findings. These are especially relevant within the context of recovery post-COVID-19. While the current debate on the recovery seems dominated by positions in favour of going back to "business-as-usual", our findings warn about the fact that economic benefits derived from tourism could go with a worsening in non-material domains, such as the health domain, especially among younger age groups and in cities, possibly related to gentrification issues. This points to the importance of fair housing and labour policies, especially for young workers and dwellers that might not yet have financial stability. Notably, the housing issue is alarming in many European cities and deserves maximum attention from local policy makers. Second, the findings challenge the narrative that urban tourism is beneficial for European citizens, and questions arise on whether, in cities, tourism-led gentrification produces more urban inequality, rather than reducing it [55]. As a consequence, these findings suggest that the negative externalities of urban tourism related to housing, labour, and quality of life deserve careful attention in research and policy contexts to avoid the spreading of anti-tourism feelings among local inhabitants, such as is already happening in cities such as Barcelona and Venice $[40,43,48]$. Third, and in relation to this, it becomes clear that tourism cannot be isolated as a policy object but should be considered together with health and equity dimensions, especially in relation to urban contexts. Given policy goals set by international bodies, of creating healthier and more equitable societies (Sustainable Development Goals number 3, 10, and 11: UN, 2015), policy makers should aim to integrate health equity reflections in urban policies of tourism and examine related exclusionary processes, with the solution potentially pointing towards de-touristification in some cases. This might hold especially valid in relation to overtouristed places, and is particularly relevant to informing debates on tourism policies and urban politics during the post-COVID-19 recovery [42].

The study has some limitations that need to be discussed. First, the results are based on pre-COVID-19 trends and data; hence, it is possible that scenarios and processes will change in the post-COVID-19 era, as will their implications. With this regard, it will also be important to monitor the effects of tourism on health and quality of life variables during the pandemic years and in the recovery period, including looking at the consequences of the lack of tourism, in addition to its existence, on the local quality of life of different groups. Second, the analyses are based on self-reported health, which is a subjective indicator. According to Michalos [56], there could be discrepancies between subjective and objective indicators, and self-reports are subject to recall and response biases. Using Michalos' [56] terminology, there is the risk that, instead of a real paradise, residents might be living in a fool's paradise. Hence, future research should employ objective indicators of health, such as mortality, for example. Third, another aspect to consider is related to the conceptualization of tourism pressure, defined as the rate of tourism stays per 1000 residents. It is possible that this led to overestimating tourism pressure in areas with low population density, such as rural areas; future research might employ specific thresholds for urban and rural areas, respectively. Fourth, the instrumental variable estimations were based on the number of Ryanair airports only, instead of low-cost carriers airports in general, because of a lack of availability of data for other low-cost carriers. Finally, these results might also be influenced by the 2008 economic crisis, as, during the study period, some of the European regions had not yet fully recovered. To overcome this, we controlled for time, regional variation, and regional GDP, and employed instrumental variable estimation to isolate our effect from external processes.

\section{Conclusions}

This study explored the effects of tourism pressure on the self-perceived health of residents at regional level, based on pan-European data from Eurostat, EU-SILC, and LFS. Differences were found in the effects of tourism on self-reported health between age groups and between degree of urbanization groups (urban, town, rural). Among younger groups (under 50-year-old) living in cities, urban tourism was associated with worsened perceived 
health. Among individuals over 50 living in rural areas and over 65 living in towns, tourism was associated with improved perceived health. Urban tourism specifically emerged as a type of tourism that can be potentially problematic for residents' health.

Overall, these heterogenous outcomes highlight that, in terms of the health impacts of tourism, there are winners and losers. Younger adults living in cities emerged as an at-risk group. We suggest that tourism-led gentrification and related increased living costs, precarious labour and conflicts related to public space, might partially explain these processes. Hence, the findings point to the need for equitable housing and labour policies in cities, especially for groups that might not be financially stable. Considering the global need for healthier and more equitable cities in the post-COVID-19 era, policy makers should consider the potentially detrimental effects of urban tourism on residents' health and quality of life.

Author Contributions: Conceptualization, A.B., S.J.V., J.v.H. and G.M.; methodology, A.B., S.J.V. and J.v.H.; formal analysis, S.J.V. and A.B.; writing—original draft preparation, A.B.; writing—review and editing, A.B., S.J.V., J.v.H., R.V. and G.M.; project administration, A.B. and G.M.; funding acquisition, G.M. All authors have read and agreed to the published version of the manuscript.

Funding: This research and APC were funded by H2020 project SMARTDEST, grant number 870753.

Institutional Review Board Statement: Not applicable.

Informed Consent Statement: Not applicable.

Data Availability Statement: A preliminary dataset is available at 10.5281/zenodo.4058290. The full dataset is available upon request.

Conflicts of Interest: The authors declare no conflict of interest.

\section{References}

1. Eurostat. Tourism. Fact Sheets on the European Union. 2021. Available online: https://www.europarl.europa.eu/ftu/pdf/en/ FTU_3.4.12.pdf (accessed on 10 January 2022).

2. Nunkoo, R.; Smith, S.L.; Ramkissoon, H. Residents' attitudes to tourism: A longitudinal study of 140 articles from 1984 to 2010. J. Sustain. Tour. 2013, 21, 5-25. [CrossRef]

3. Uysal, M.; Sirgy, M.J.; Woo, E.; Kim, H.L. Quality of life (QOL) and well-being research in tourism. Tour. Manag. 2016, 53, $244-261$. [CrossRef]

4. World Tourism Organization (WTO). Guide for Local Authorities on Developing Sustainable Tourism; World Tourism Organization: Madrid, Spain, 1998.

5. Perdue, R.R.; Long, P.T.; Kang, Y.S. Resident support for gambling as a tourism development strategy. J. Travel Res. 1995, 34, 3-11. [CrossRef]

6. Ivlevs, A. Happy hosts? International tourist arrivals and residents' subjective well-being in Europe. J. Travel Res. 2017, 56, 599-612. [CrossRef]

7. Damasio, A.R. Descartes' error and the future of human life. Sci. Am. 1994, 271, 144. [CrossRef]

8. Helliwell, J.; Layard, R.; Sachs, J. World Happiness Report 2017 (Ser. Canadian Public Documents Collection). Center for Sustainable Development. 2017. Available online: https://worldhappiness.report/ed/2017/ (accessed on 10 January 2022).

9. Gursoy, D.; Jurowski, C.; Uysal, M. Resident attitudes: A structural modeling approach. Ann. Tour. Res. 2002, 29, 79-105. [CrossRef]

10. Gjerald, O. Sociocultural impacts of tourism: A case study from Norway. J. Tour. Cult. Change 2005, 3, 36-58. [CrossRef]

11. Yamada, N.; Heo, J.; King, C.; Fu, Y.Y. Life satisfaction of urban residents: Do health perception, wealth, safety, community pride and, and cultural tourism matter? In Proceedings of the International CHRIE Conference-Refereed Track, San Francisco, CA, USA, 31 July 2009; p. 24.

12. Rivera, M.; Croes, R.; Lee, S.H. Tourism development and happiness: A residents' perspective. J. Destin. Mark. Manag. 2016, 5, 5-15. [CrossRef]

13. Nawijn, J.; Mitas, O. Resident attitudes to tourism and their effect on subjective well-being: The case of Palma de Mallorca. J. Travel Res. 2012, 51, 531-541. [CrossRef]

14. Matarrita-Cascante, D.; Brennan, M.A.; Luloff, A.E. Community agency and sustainable tourism development: The case of La Fortuna, Costa Rica. J. Sustain. Tour. 2010, 18, 735-756. [CrossRef]

15. Godovykh, M.; Ridderstaat, J. Health outcomes of tourism development: A longitudinal study of the impact of tourism arrivals on residents' health. J. Destin. Mark. Manag. 2020, 17, 100462. [CrossRef] 
16. Tokarchuk, O.; Gabriele, R.; Maurer, O. The impact of tourism on the wellbeing of residents. In Proceedings of the 21st Excellence in Services International Conference (EISIC), Paris, France, 30-31 August 2018; pp. 679-692.

17. Okulicz-Kozaryn, A.; Strzelecka, M. Happy tourists, unhappy locals. Soc. Indic. Res. 2017, 134, 789-804. [CrossRef]

18. UNCTAD (United Nations Conference on Trade and Development). Sustainable Tourism-A Tool for Development and Poverty Eradication. 2017. Available online: https://unctad.org/news/sustainable-tourism-tool-development-and-poverty-eradication (accessed on 10 January 2022).

19. Dahlgren, G.; Whitehead, M. Policies and Strategies to Promote Social Equity in Health; Background Document to WHO-Strategy Paper for Europe; No. 2007: 14; Institute for Futures Studies: Stockholm, Sweden, 1991.

20. Hayes, M.; Zaban, H. Transnational gentrification: The crossroads of transnational mobility and urban research. Urban Stud. 2020, 57, 3009-3024. [CrossRef]

21. Cocola-Gant, A. Tourism gentrification. In Handbook of Gentrification Studies; Edward Elgar Publishing: Cheltenham, UK, 2018.

22. Riganti, P.; Nijkamp, P. Congestion in popular tourist areas: A multi-attribute experimental choice analysis of willingness-to-wait in Amsterdam. Tour. Econ. 2008, 14, 25-44. [CrossRef]

23. Gotham, K.F. Tourism gentrification: The case of new Orleans' Vvieux Ccarrée (French Quarter). Urban Stud. 2005, 42, 1099-1121. [CrossRef]

24. Nguyen TT, M.; Rahtz, D.; Shultz, C. Tourism as catalyst for quality of life in transitioning subsistence marketplaces: Perspectives from Ha Long, Vietnam. J. Macromark. 2014, 34, 28-44.

25. World Tourism Organization (WTO); International Labour Organization (ILO). Measuring Employment in the Tourism IndustriesGuide with Best Practices; UNWTO: Madrid, Spain, 2014.

26. Croezen, S.; Burdorf, A.; van Lenthe, F.J. Self-perceived health in older Europeans: Does the choice of survey matter? Eur. J. Public Health 2016, 26, 686-692. [CrossRef] [PubMed]

27. SMARTDEST. The SMARTDEST Project. 2021. Available online: www.smartdest.eu (accessed on 10 January 2022).

28. Vermeulen, S.; Bornioli, A.; Liedl, B.; Alexander, L.; Kazepov, Y.; Mocca, E.; Russo, A.P.; Valente, R.; Brandajs, F. SMARTDEST DATASET WP2 V1 [Data set]. Zenodo 2020. [CrossRef]

29. Eurostat. Degree of Urbanization. 2019. Available online: https://ec.europa.eu/eurostat/web/degree-of-urbanisation/ background (accessed on 10 January 2022).

30. R Core Team. R: A Language and Environment for Statistical Computing; R Foundation for statistical Computing: Vienna, Austria, 2020; Available online: https:/ / www.R-project.org/ (accessed on 10 January 2022).

31. Lahti, L.; Huovari, J.; Kainu, M.; Biecek, P. Retrieval and Analysis of Eurostat Open Data with the eurostat Package. $R$ J. 2017, 9, 385. [CrossRef]

32. Wickham, H.; Averick, M.; Bryan, J.; Chang, W.; McGowan LD, A.; François, R.; Yutani, H. Welcome to the Tidyverse. J. Open Source Softw. 2019, 4, 1686. [CrossRef]

33. Pebesma, E.J. Simple features for R: Standardized support for spatial vector data. $R$ J. 2018, 10, 439. [CrossRef]

34. Bornioli, A.; Russo, A.P.; Vermeulen, S.; Valente, R.; The Spatial Articulation and Local Effects of Tourism and Associated Mobilities. SMARTDEST Report. 2020. Available online: https://smartdest.eu/wp-content/uploads/2021/01/SMARTDESTD2 .2-FULLVERSION-Spatialarticulationlocaleffectstourism-merged.pdf (accessed on 10 January 2022).

35. Eurostat. European Union Statistics on Income and Living Conditions (EU-SILC). 2021. Available online: https:// ec.europa.eu/ eurostat/web/microdata/european-union-statistics-on-income-and-living-conditions (accessed on 10 January 2022).

36. Schmidt-Catran, A.W.; Fairbrother, M. The random effects in multilevel models: Getting them wrong and getting them right. Eur Sociol. Rev. 2016, 32, 23-38. [CrossRef]

37. Swanson, S.A.; Hernán, M.A. Commentary: How to report instrumental variable analyses (suggestions welcome). Epidemiology 2013, 24, 370-374. [CrossRef]

38. Staiger, D.; Stock, J.H. Instrumental variables regression with weak instruments. Econom. J. Econom. Soc. 1997, 65, 557-586. [CrossRef]

39. Meng, F.; Li, X.; Uysal, M. Tourism development and regional quality of life: The case of China. J. China Tour. Res. 2010, 6, 164-182. [CrossRef]

40. Sánchez-Ledesma, E.; Vásquez-Vera, H.; Sagarra, N.; Peralta, A.; Porthé, V.; Díez, È. Perceived pathways between tourism gentrification and health: A participatory Photovoice study in the Gòtic neighborhood in Barcelona. Soc. Sci. Med. 2020, 258, 113095. [CrossRef]

41. Cocola-Gant, A.; Gago, A. Airbnb, buy-to-let investment and tourism-driven displacement: A case study in Lisbon. Environ. Plan. A Econ. Space 2019, 53, 1671-1688. [CrossRef]

42. Milano, C.; Koens, K. The paradox of tourism extremes. Excesses and restraints in times of COVID-19. Curr. Issues Tour. 2021, 1-15. [CrossRef]

43. Russo, A.P.; Scarnato, A. "Barcelona in common": A new urban regime for the 21st-century tourist city? J. Urban Aff. 2018, 40, 455-474. [CrossRef]

44. Mehdipanah, R.; Marra, G.; Melis, G.; Gelormino, E. Urban renewal, gentrification and health equity: A realist perspective. Eur. J. Public Health 2018, 28, 243-248. [CrossRef] [PubMed]

45. Lacher, R.G.; Oh, C.O. Is tourism a low-income industry? Evidence from three coastal regions. J. Travel Res. 2012, 51, 464-472. [CrossRef] 
46. Marcouiller, D.W.; Kim, K.K.; Deller, S.C. Natural amenities, tourism and income distribution. Ann. Tour. Res. 2004, 31, 1031-1050. [CrossRef]

47. Brandajs, F.; Russo, A.P. Whose is that square? Cruise tourists' mobilities and negotiation for public space in Barcelona. Appl. Mobilities 2019, 289-313. [CrossRef]

48. Quinn, B. Performing tourism Venetian residents in focus. Ann. Tour. Res. 2007, 34, 458-476. [CrossRef]

49. Gibbons, J.; Barton, M.S. The Association of Minority Self-Rated Health with black versus white gentrification. J. Urban Health 2016, 93, 909-922. [CrossRef] [PubMed]

50. Jelks, N.T.O.; Jennings, V.; Rigolon, A. Green gentrification and health: A scoping review. Int. J. Environ. Res. Public Health 2021, 18, 907. [CrossRef]

51. Kadi, J.; Plank, L.; Seidl, R. Airbnb as a tool for inclusive tourism? Tour. Geogr. 2019, 1-23. [CrossRef]

52. Barron, K.; Kung, E.; Proserpio, D. The Sharing Economy and Housing Affordability: Evidence from Airbnb. In Proceedings of the 2018 ACM Conference on Economics and Computation, Ithaca, NY, USA, 18-22 June 2018; p. 5.

53. Rickly, J.; Hannam, K.; Mostafanezhad, M. (Eds.) Tourism and Leisure Mobilities: Politics, Work, and Play; Routledge: London, UK, 2016.

54. Smith, G.S.; Breakstone, H.; Dean, L.T.; Thorpe, R.J. Impacts of gentrification on health in the US: A systematic review of the literature. J. Urban Health 2020, 97, 845-856. [CrossRef]

55. McCartney, G.; Hearty, W.; Taulbut, M.; Mitchell, R.; Dryden, R.; Collins, C. Regeneration and health: A structured, rapid literature review. Public Health 2017, 148, 69-87. [CrossRef]

56. Michalos, A.C. The impact of trust on business, international security and the quality of life. In Essays on the Quality of Life; Springer: Dordrecht, The Netherlands, 2003; pp. 391-415. 